\title{
DINÁMICA SOCIOINTERCULTURAL DEL SURGIMIENTO DEL PUERTO DE TOPOLOBAMPO EN MÉXICO
}

\section{Socio-intercultural dynamics of the emergnce of the port of Topolobampo in Mexico}

\author{
Ernesto Guerra-García*; María Azucena Caro-Dueñas**; \\ Ana Luiza Corrales-Baldenebro***
}

Recibido:07 de marzo. 2020. Aceptado: 30 de junio de 2020. Publicado: 01 de julio 2020.

Forma de citar este artículo en APA:

Guerra-García, E., Caro-Dueñas, M. A., Corrales-Baldenebro A. L., (2020, julio-diciembre). Dinámica sociointercultural del surgimiento del puerto de Topolobampo en México. Revista CoPaLa, Construyendo Paz Latinoamericana 10 (año 5), pp. $102-125$. DOI:10.35600.25008870.2020.10.0174, Recuperado desde: http://revistacopala.net/index.php/ojs/article/view/22

\section{Resumen}

Se analiza la dinámica sociointercultural del surgimiento del puerto de Topolobampo en México, con la instalación de una colonia estadounidense. Se propuso hacer una descripción desde dos aristas que dan muestra del complejo fenómeno sociohistórico: una partiendo de las relaciones interculturales y la otra desde las intenciones políticas. Se encontró que, en la primera, el racismo ejecutado, tanto por los colonos americanos como por los mexicanos en perjuicio de los indígenas yoremes de la localidad, se presentaba ante jerarquías de color y de estatus económico. La instalación de los colonos ayudó a reforzar las clases sociales en la localidad. En la segunda, la práctica de la colonia siempre estuvo matizada por grandes negocios y no era ajena a preceptos racistas y discriminadores. El hecho es que las condiciones estuvieron propicias para una invasión justificada por los negocios y la adquisición desmedida de territorio, la contradicción con la práctica socialista de la colonia y el involucramiento de personajes de altas esferas políticas de México y de Estados Unidos.

\section{Palabras clave}

Sociointerculturalidad, Topolobampo, Owen, racismo, yoremes y colonos

\footnotetext{
* Doctor en Enseñanza Superior, Profesor-investigador. Coordinación General de Investigación y posgrado, Universidad Autónoma Indígena de México. drguerragarcia@gmail.com

** Doctorante en Educación para la Diversidad Cultural. Profesora-Investigadora Coordinación General de Investigación y posgrado, Universidad Autónoma Indígena de México. caroazucena@gmail.com

*** Doctora en Educación para el Desarrollo Humano. Profesora-Investigadora, Coordinación General de Investigación y posgrado, Universidad Autónoma Indígena de México. icha1990_8@hotmail.com
} 


\section{Abstract}

The socio-cultural dynamics of the emergence of the Topolobampo port in Mexico are analyzed, with the installation of a US colony. It was proposed to make a description from two edges that show the complex sociohistorical phenomenon: one starting from intercultural relations and the other from political intentions. It was found that, in the first, the racism carried out, by both the American and Mexican settlers to the detriment of the local Yoreme indigenous people, was presented before hierarchies of color and economic status. The installation of the colonists helped to reinforce the social classes in the locality. In the second, the practice of the colony was always nuanced by big business and was not alien to racist and discriminatory precepts. The fact is that the conditions were conducive to an invasion justified by business and the excessive acquisition of territory, the contradiction with the socialist practice of the colony and the involvement of figures from high political spheres in Mexico and the United States.

\section{Keywords}

Sociointerculturality, Topolobampo, Owen, racism, yoremes and colonists. 


\section{Introducción}

En 1886 inició en México el asentamiento de una colonia de carácter socialista con migrantes procedentes principalmente de los Estados Unidos de América, en Topolobampo, al norte del Estado de Sinaloa; después de casi diez años la experiencia terminó dejando múltiples aprendizajes y un innegable impacto en la zona de influencia.

Se utiliza un enfoque socio-intercultural, no sólo porque se aborda la perspectiva sociológica, sino porque el fenómeno sociohistórico presenta aspectos que van más allá de las relaciones interculturales; la sociedad y la cultura se encuentran siempre imbricadas, para Bordeau (citado por García, 2004), la sociedad está estructurada con base en dos tipos de relaciones: las de la fuerza, referidas al valor de uso y de cambio y que abarcan, de manera entretejida otro tipo de relaciones, que son las de sentido, responsables de la organización de las relaciones de significación en la vida social; éstas últimas constituyen la cultura. Pero como en este caso se presenta a través de relaciones entre diferentes culturas se habla de una socio-interculturalidad.

También se aborda desde una perspectiva de la complejidad, no en el sentido de que sea inentendible, sino en el que las descripciones no son simples, donde los tejidos pueden presentar diversas tramas en las que sólo se seleccionó seguir dos aspectos. 1. Las relaciones interculturales entre estadounidenses, mexicanos y Yoremes, y 2. Las intenciones políticas. Las técnicas utilizadas fueron el análisis documental y la entrevista a los habitantes de Topolobampo y de la región que mantenían evidencias de lo sucedido.

\section{Antecedentes a la colonia}

En 1872 el ingeniero estadounidense Albert Kinsey Owen participó en una expedición a la costa del pacífico mexicano de los estados de Sonora, Sinaloa y Jalizco (Owen, 1890); los americanos eran bien vistos por el gobierno de Juárez, a pesar de la reciente guerra con Estados Unidos, pues había sido apoyado por éstos ante la invasión francesa. Al llegar a Mazatlán y estando en compañía de altas personalidades norteamericanas, tales como el cónsul Benjamín R. Carman y el hijo del expresidente Grant, plantearon algunas posibilidades en la zona, particularmente en un lugar en Sinaloa-llamado Topolobampo, del que podía partir un tren hacia Texas y adentrarse a los Estados Unidos (Martínez, 2000). Al parecer se trataba de establecer rutas de conexión por ferrocarril desde el pacífico para facilitar mercancías que provenían de oriente (Figura 1). 
Topolobamo era el nombre que los yoremes (indígenas del norte de Sinaloa) habían dado a ese lugar. Según el listado toponímico de Ochoa (2018), las palabras terminadas en 'Bampo' se relacionan con elementos que se encuentran en el agua; por ejemplo, Macochibampo significa Guamúchil (una planta) en el agua, Cochibampo es camarón en el agua, Bachomobampo es batamotes (otra planta) en el agua, etcétera. Actualmente, la mayoría desconoce el significado; algunos dicen que es una mezcla de español y yoremnokki (la lengua de los yoremes) y se puede interpretar como 'topo en el agua'; otros dicen que se hace referencia a un vocablo antiguo cuando 'topolo' era el nombre que se le daba al lince, muy común en la región; así si nos apegamos a este último criterio, Topolobampo puede significar «lince en el agua».

Figura 1. Rutas de conexión del pacífico a las ciudades Industriales de los Estados Unidos. En blanco los territorios que le fueron

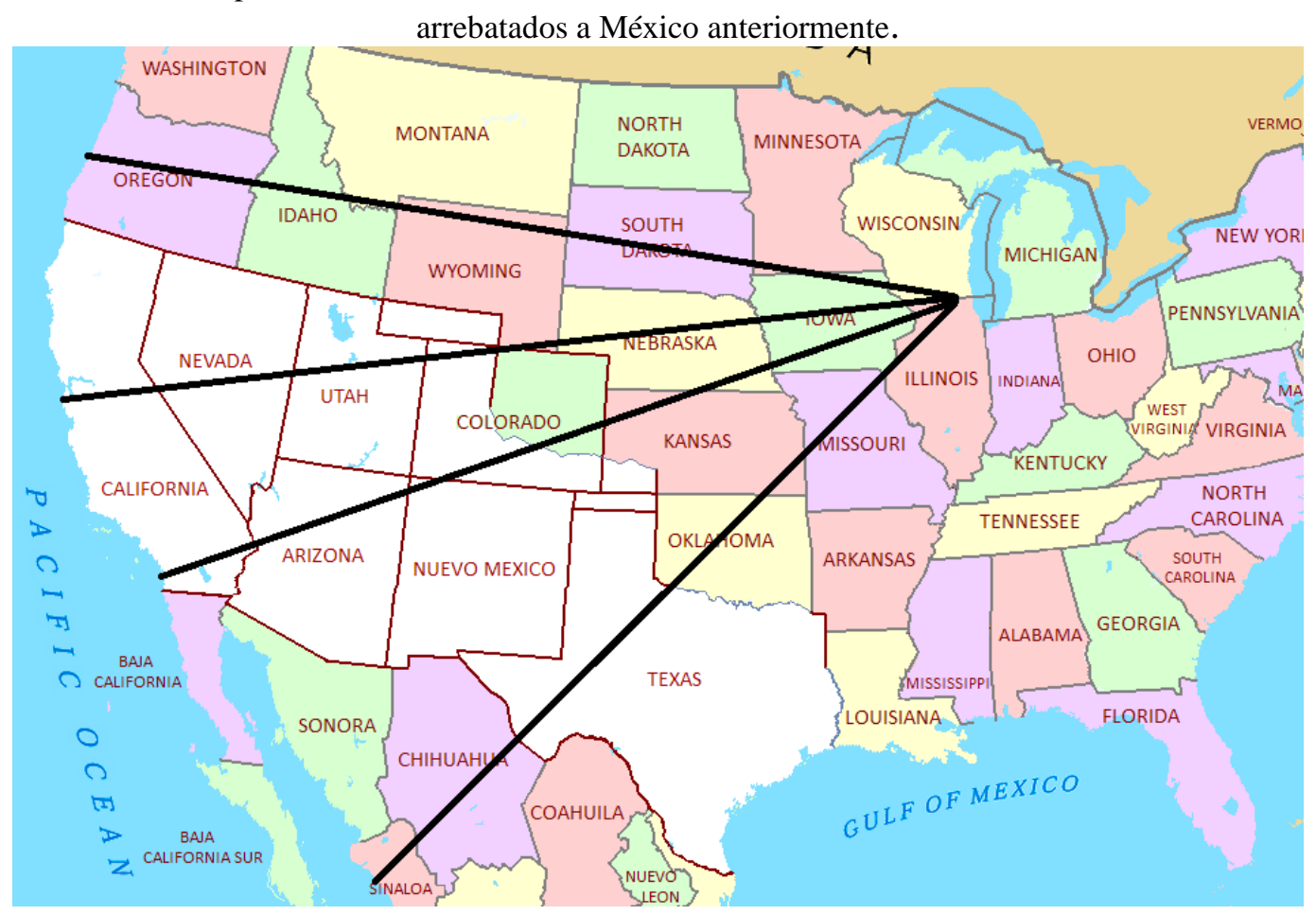

Fuente: Construcción propia, con base en la figura diseñada por Martínez (2000).

En Sinaloa, los yoremes habían -y han estado- habitado la fracción norte de la entidad repartiéndose en lo que ahora son seis municipios: Ahome (lugar donde se encuentra asentado Topolobampo), Angostura, Choix, El Fuerte, Guasave y Sinaloa de Leyva (López, 2007).

Estando Owen en Mazatlán, se enteró del fallecimiento de Juárez y de la suspensión de los programas de construcción de ferrocarriles, a los que había estado invitado años atrás (Martínez, 2000). Pero continuó con la idea de ir a Topolobampo y desarrollar el proyecto.

El 20 de septiembre de 1872 llegó junto con otros norteamericanos a Topolobampo y confirmaron que era el lugar exacto para construir un puerto y una ruta ferroviaria. De acuerdo con él había sólo pequeños grupos de 
indios en el valle que ocasionalmente pescaban y capturaban tortugas de mar, de hecho, uno de ellos le dio un paseo en la bahía y así fue como se percató de su belleza y de la inigualable localización y acceso (Kinney, 2016).

Al regresar a Mazatlán fundó una empresa (de deslinde de terrenos) en asociación con un inversionista sinaloense para el desarrollo del proyecto. La clave se encontraba en el marco legal para la disponibilidad y apropiación de tierras a través del llamado denuncio, mediante el que se podía denunciar "terrenos baldíos" (en su mayoría eran originariamente de los yoremes) para comprarlos al gobierno con la intención de hacerlos producir (Martínez, 2000). El denuncio de terrenos estaba regulado por la Ley sobre Ocupación y Enajenación de Terrenos Baldíos (decreto de gobierno de Benito Juárez de 1863).

En ese mismo año 1872, Sebastián Lerdo de Tejada asumió la presidencia y continuó con la política de usar las tierras que pertenecían a las comunidades indígenas, con el pretexto de que eran incapaces de explotarlas adecuadamente. Se trataba de ideas desarrollistas que buscaban la apertura al capital internacional, la construcción de vías férreas para favorecer el traslado de mercancías y la cesión de tierras a colonos extranjeros. El proyecto de Owen contemplaba no sólo Topolobampo, sino todas las tierras fértiles que otrora pertenecían a los Yoremes, incluyendo lo que hoy es Los Mochis, Sinaloa (Ochoa, 2018).

Desde 1874, Owen fue repetidas veces al Comité del Senado norteamericano con el propósito de pedir un análisis del terreno para su ferrocarril que pasaba por Texas desde México; ahí el general Grant decidió ordenar una revisión completa de la bahía de Topolobampo (Valadés, 1939). El hecho de que un general estadounidense tan influyente, tomara este tipo de decisión evidencia el grado de intervencionismo que aún tenía Estados Unidos en nuestro país.

A partir de ahí, su intención fue adquirir grandes extensiones de tierras que serían beneficiadas por el ferrocarril, cosa que consiguió gracias a la política etnofágica con que el gobierno justificaba la distribución de las tierras nacionales.

Topolobampo pertenecía a los yoremes, quizá no como residencia, pero sí como territorio de caza, como era el caso de la zona los motchim (Mochis) y de pesca, como lo era el vaviri (Maviri), que de ninguna manera eran desérticos, como se argumentaba, y no estaban baldíos, como se aseguraba. De hecho, no fue Owen el primero en vislumbrar las posibilidades de tener amplias extensiones de tierra, Ochoa (2018) menciona que otros extranjeros ya se habían hecho de grandes extensiones de tierras sinaloenses. Este hecho provocó el recrudecimiento de la guerra con los yoremes, que alcanzó una de sus etapas más crueles y violentas. Yaquis 
y mayos se levantaron en armas bajo la dirección de Cajeme y luego de Tetabiate, para luchar en defensa de sus tierras. Las acciones militares ocurrieron principalmente en territorio de Sonora, pero participaron en el conflicto los yoremes del Valle del Fuerte, quienes después de su derrota fueron deportados a Yucatán y Oaxaca (Gouy-Gilbert, 1985).

Es necesario aclarar que aún mucho después de la independencia mexicana en 1810, muchos pueblos indígenas no se declaraban como mexicanos y el gobierno había declarado la guerra (formal o informalmente) contra algunas etnias, las más conocidas de todas fueron las de los apaches y los yoremes (también llamados cahitas). En 1879, Owen fue presentado con el presidente Porfirio Díaz y aprovechó la oportunidad de presentar la idea del ferrocarril Texas Topolobampo (Martínez, 2000). Pero fue hasta 1881 que Owen obtuvo la concesión para construir el sistema ferroviario de Topolobampo y la ciudad socialista que primero llamaría «González City», en honor al presidente que continuó por algunos años, Manuel González (Martínez, 2000). El asunto ferroviario era prioridad en nuestro país. Hay que advertir que, si bien México no tenía la tecnología ni el recurso económico para construir las vías ferroviarias y poner en marcha los ferrocarriles, la intromisión de empresas estadounidenses ponía en peligro la soberanía nacional.

Es importante no dejar pasar que, en 1874 Mary Stevens Case Howland publicó su novela 'Papa's own girl', una obra pionera en el movimiento feminista que promovía la independencia económica de la mujer, el amor libre, la libertad sexual y la vida comunitaria, ideas totalmente revolucionarias en su tiempo y que llamaron la atención del joven A.K. Owen, quien visitó a los esposos Howland en 1875 (Iribarne, 2020).

En 1883, los comunistas en el mundo se encontraban de luto; la muerte de Carlos Marx revivió el socialismo utópico de Robert Owen (1771-1858), de Henri de Saint-Simon (1760-1825) y de Charles Fourier (1772-1837), entre muchos otros, que dejaron de legado esquemas sociales que en su momento se volvieron importantes movimientos, como el cooperativismo, las ecoaldeas y el feminismo, entre otros (García, López y Ruiz, 2000). Esta idea del cooperativismo integral y autosuficiente era la que Albert Owen había vislumbrado para Topolobampo, como ciudad socialista.

Con estos antecedentes, Albert Owen inició en 1884 la campaña de reclutamiento para la colonización de Topolobampo. Siendo ya copropietario de tierras en el norte de Sinaloa, inició la construcción del ferrocarril y la nivelación de los terrenos. En 1885, creó la Credit Foncier Company que se regía por la legislación del estado de Colorado en Estados Unidos (Nakayama, 1996) y que se encargaría de proporcionar todo lo que la gente necesitara: comida, educación, ropa, etcétera, en una idea de participación equitativa. A través de esta empresa Owen, logró colocar algunos de los doscientos mil bonos de 10 dólares para construir el ferrocarril y 
de la colonia cooperativa que ahora se llamaría Pacific City (Katscher, 1906). En apariencia, su intención era usar ese financiamiento para el proyecto de colonización, pero sus operaciones no estuvieron desprovistas de hacer grandes negocios.

El 19 de junio de 1985 los reconocidos socialistas que acompañaban a Albert Owen -el Dr. Edward Howland y su esposa Marie- empezaron la publicación del periódico oficial The Crédit Foncier of Sinaloa. Marie y Edward ya habían participado en una comunidad igualitaria, en Francia, en un Familisterio; habían estudiado prácticamente todas las teorías del socialismo y el comunitarismo y estaban seguros de que era posible crear una comunidad de hombres y mujeres libres, socios entre sí, sin las perversiones del capitalismo (Mejía, 2011).

Además, promovieron, como ya se había mencionado las ideas feministas de igualdad de género, independencia económica y sobre todo libertad sexual; Marie promovía que la mujer podía decidir su relación amorosa libre sin el prejuicio social (Iribarne, 2020). Esto no quiere decir que así es como se constituyó la colonia, de hecho, en la práctica tendió a ser más conservadora y tratando de seguir los usos y costumbres de los sinaloenses de aquel entonces.

\section{La colonia americana}

Ya para noviembre de 1886 se encontraban instalados y organizados los primeros 187 colonos (Martínez, 2000), quienes dejaron muchas cosas importantes en sus vidas por perseguir un sueño utópico, pasaron por muchas inclemencias y llegaron a un lugar que, a pesar de su belleza natural, presentaba adversidades a los que no estaban acostumbrados. Socialmente, llegaron de manera pacífica entablando buenas relaciones con los lugareños (García, 2020), hacían un esfuerzo por tener ese sentido de pertenencia mexicano, realizaban algunas acciones de lo que ellos pensaban que era la mexicanidad y estaban pendientes de cómo eran vistos por los mexicanos (Kinney, 2016).

Sin embargo, es de anotar que aun cuando pudo haber existido un buen trato, las estructuras racistas estaban constituidas desde antaño; desarrollaron relaciones con mexicanos de clases sociales principalmente altas. Algunos colonos como Marie y otras amigas visitaban y eran visitadas por familias encumbradas de la región. Durante el porfiriato se presentaban básicamente dos culturas, la de la élite que creía en el progreso, la eficiencia y la modernidad y el resto de mexicanos entre ellos los indígenas que apenas sobrevivían. La elite mexicana (sinaloense) veía la oportunidad de compartir su cultura con los estadounidenses debido a su estatus de extranjeros, blancos, normalmente educados y progresistas ya que encajaban perfectamente con las ideas de clase que dividían a la sociedad mexicana; al igual que los colonos estaban 'consternados' por el atraso de la población indígena (Kinney, 2016). 
Cuando no se dimensionaban los efectos históricos de la conquista, del despojo de tierras y de las consecuencias de la violencia étnica, parecía inexplicable la deplorable condición de los yoremes, incluso se pensaba que era debido a su propia cultura.

Los colonos enseñaban inglés a los niños de las personas más ricas, así como de ideales progresistas tanto en la escuela de la colonia como fuera de ella. Recibían a los estudiantes mexicanos que pagaban por los servicios; Scally por ejemplo, además de inglés, impartía álgebra, geometría y trigonometría en las casas de los ricos hacendados. Como muestra de la relación desigual se registra que algunos niños indígenas - de piel obscura, decían - con frecuencia venían a la escuela, pero no participaban mientras se impartían clases, observaban desde una pequeña distancia sonriendo, pero permaneciendo quietos (Kinney, 2016).

Sin embargo, desde la perspectiva de los funcionarios mexicanos, la idea era que los colonos tuvieran una mayor relación con los indios, su interés era el mejoramiento y el progreso de la raza a partir de la influencia anglosajona y escandinava, específicamente en los asuntos de la inteligencia (Kinney, 2016).

Ante esta circunstancia la posición de los colonos no era de privilegio, no todos los editorialistas de la época pensaban que la modernización y el progreso vendrían adicionando la fuerza racial de los nort-europeos y americanos blancos. Algunos preferían la inmigración latina de europa, francesa, italiana y portuguesa, de aquellos países que podían armonizar mejor con la población y asimilarse de una mejor manera para crear una nacionalidad homogénea, más fácilmente gobernable. De esta forma los inmigrantes anglosajones eran discriminados por algunos porque no servirían a los propósitos esperados (Kinney, 2016).

De las ideales condiciones que Owen promovía a la realidad del clima del norte de Sinaloa había una gran diferencia: el excesivo calor, los mosquitos, los ciclones; las dificultades con los terratenientes hicieron que él mismo no soportara ni cuatro meses en la colonia y, con el pretexto de conseguir recursos, no volviera sino hasta 1890 (Mejía, 2011).

Mientras tanto, los yoremes experimentaban los fuertes contrastes sociales. El gobierno los había despojado de sus tierras «baldías» para vendérselas a los colonos estadounidenses, entre ellos a Owen y a un grupo de notables no indígenas de la región. La polarización de la riqueza produjo fuertes contrastes sociales y reacciones de inconformidad que eventualmente producían surgimientos armados, como el de Heraclio Faustino Petronilo Bernal Zazueta, el Rayo de Sinaloa. 
A principios de 1887, la región contaba con más de 400 pioneros y en agosto arribó otro grupo, por lo que la población llegó a 700 habitantes. Es posible que en su mayoría no eran socialistas, pero veían en las facilidades del gobierno mexicano una buena oportunidad que quizá en ese momento no encontraban en Estados Unidos. Lo que sí es que traían esa inercia de los primeros pioneros que invadieron las tierras indias norteamericanas; venía gente de diferentes clases sociales y diferente nivel de preparación, de tal manera que debió haber sido difícil convivir entre personas con ideas distintas, aun cuando pareciera que los preceptos socialistas darían cierto orden a la organización de la colonia.

A pesar de estas inercias, algo muy importante para la historia del racismo es que la colonia rápidamente desarrolló una reputación (en los Estados Unidos) de estar en contra de los prejuicios raciales, no sólo con los mexicanos, sino también con negros y chinos (Kinney, 2016, p. 113).

En 1888, gracias a los trabajos de los colonos, Topolobampo quedó habilitado como puerto de cabotaje y Owen recibió, del presidente Díaz, otra prórroga para seguir con los proyectos. Al siguiente año, festejaron en grande su tercer año de haber llegado (Martínez, 2000).

En ese mismo año, 1888, Owen conoce y se asocia con Christian B. Hoffman, un rico industrial de Kansas, quien tenía un sentido más práctico en los negocios. A partir de ahí inició una nueva etapa en la vida de la colonia; su presencia le dio un impulso diferente al proyecto, fortaleció obras de irrigación y creó algunas empresas. Aquí es donde Hoffman le plantea a Owen dar un giro a la causa utópica y crear la empresa Kansas Sinaloa Investment Company, que se dedicaría a adquirir terrenos para después colonizarlos (Moore, 1975). Los colonos que venían con Hoffman no eran socialistas; buscaban tierras privadas y no se pudieron integrar a las ideas de la comuna (Mejía, 2011).

Mientras tanto y entre paréntesis, dos hechos clave para la posterior fundación de Los Mochis en 1890 fueron: (1) el arribo de Benjamin Johnston en esa época de oleada de inmigrantes norteamericanos que llegaban al proyecto de Owen y (2) la compra de 4500 hectáreas de terrenos por la Kansas Sinaloa Investment Company (Martínez, 2000) en el predio que los yoremes llamaran Mochimpo y que se castellanizó como Los Mochis (Ochoa, 2000).

Como ya se había notado, no sólo Owen se hizo de tierras en el norte de Sinaloa, sino que diversos terratenientes también aprovecharon las oportunidades que las leyes gubernamentales habían proveído. 
Mientras en 1890 la colonia continuaba con el flujo inmigratorio estadounidense, Owen consiguió «nuevamente» firmar el contrato para establecer la colonia modelo ahora llamada Pacific City y una prórroga para el proyecto ferrocarrilero (Ortega, 1999). Desafortunadamente en diciembre de este año falleció el Dr. Howland, lo que significó una gran pérdida del liderazgo del socialismo como filosofía de base en la colonia. A partir de ahí, la colonia empezó a perder su esencia; los seguidores de Hoffman, que no reconocían la idea socialista de la cooperación integral, exigían la aplicación de los principios capitalistas comenzando con la titulación individual de tierras (Martínez, 2000).

En 1892, Owen regresó a Topolobampo para atender una asamblea en la que dio un discurso y pudo percibir el malestar de la gente (Moore, 1975); para1893, los problemas en la colonia eran cotidianos, pero el principal era la pugna entre los dos bandos que se habían formado, los que estaban con la idea inicial del socialismo utópico y los que seguían a Hoffman con sus nuevos proyectos capitalistas (Martínez, 2000).

Mientras esto sucedía, se trazaban las primeras calles del predio Los Mochis, se abrió la compuerta del canal que tanto anhelaban los colonos y que solucionaría gran parte de sus problemas de abasto de agua. Estos hechos, que años atrás hubieran significado la consolidación de la comunidad, marcaron en realidad el principio del fin de la utopía (Moore, 1975).

La situación llegó a su clímax cuando esta problemática escaló a nivel gubernamental y Owen se enfrentó al gobernador, quien se había inclinado a favor de Hoffman. Ese año (1893) Owen, regresó a Estados Unidos y jamás regresó. El fin del endeble pensamiento socialista utópico en la colonia sucedió, no con la partida de Owen, sino cuando Marie Howland se embarcó desde Topolobampo en ese mismo año. A pesar de que la empresa Credit Foncier Company caducó en 1896, Owen publicaría posteriormente, en 1897, un último folleto A Dream of an Ideal City, en donde insistía en que aún era posible construir una ciudad ideal (Ortega, 1999).

\section{Eventos posteriores a la colonia}

Mientras los colonos se dispersaban, es importante resaltar que Estados Unidos participó en 1895 apoyando la guerra de independencia de Cuba y que esto le ocasionó un conflicto Bélico con España en 1898, del que al salir victorioso se hace de Puerto Rico, Filipinas y Guam, lo que minimizó la tensión en las relaciones MéxicoEstados Unidos (Pérez, 2000).

A partir de 1900, en pleno apogeo del imperialismo norteamericano, se construyeron de manera más intensiva el Ferrocarril Chihuahua al Pacífico y el actual Ferrocarril del Pacífico, que comunicó directamente con Sonora 
y la frontera estadunidense, y en 1901 el poderoso magnate Johnston mandó trazar calles amplias y rectas, muy al estilo norteamericano, en lo que hoy es la ciudad de Los Mochis (Martínez, 2000).

En 1902, ya sin la colonia, se abrió Topolobampo como puerto de altura y en 1903 se fundó la alcaldía de la importante ciudad de Los Mochis, debido a la gran población que atrajo la empresa agroindustrial de Johnston. El 20 de noviembre de 1910 en México, Francisco I. Madero publicó el Plan de San Luis Potosí, donde denunció a Díaz y se proclamó presidente. Así es como empezó la Revolución Mexicana (Santana, 2007). Para 1913, los colonos habían perdido la concesión de las tierras; estas y el sistema de riego pasaron a manos de Johnston; algunos de ellos se quedaron en Los Mochis; otros se dispersaron en diversos puntos del valle o volvieron a Estados Unidos (Martínez, 2000).

En plena Primera Guerra Mundial, las rebeliones indígenas continuaban en el norte de Sinaloa. En octubre de 1914, el entonces presidente Venustiano Carranza nombró a Manuel Rodríguez Gutiérrez gobernador provisional de Sinaloa, quien, convencido de que la rebelión indígena tenía como raíz el despojo de las tierras comunales, este concibió un plan de reforma agraria para responder a las demandas de los campesinos sinaloenses. De esta manera, el reparto de tierras a los indígenas había iniciado en 1915, pero los terratenientes solicitaron el retiro del gobernador, argumentando que este desconocía los problemas de Sinaloa por ser originario de Coahuila (Ortega, 1999).

De esta manera comenzó una rebelión más fuerte de los yoreme mayo encabezada por Felipe Bachomo, quien atacó repetidas veces la población de Los Mochis, pero fue capturado y fusilado en 1916. Así se perdió toda esperanza de recuperación de las tierras que otrora fueran el sustento de la gran nación yoreme (Ochoa, 2000). Quizá el despojo de las tierras indígenas no fue iniciado por Owen, pues varios terratenientes no indígenas ya tenían en su poder estos recursos antes de su arribo al territorio. Pero su llegada a Topolobampo intensificó la etnofagia y el racismo que prevalece en este lugar.

Owen falleció en 1916 a la edad de 69 años y con ello se pone fin a este fragmento histórico.

\section{Antecedentes históricos de los yoremes}

La colonia americana se estableció en la histórica etnorregión yoreme mayo, aun cuando el territorio ya había sido tomado por no indígenas. Se alude a una etnorregión debido a que (1) existía y sigue existiendo un territorio y un espacio signado por una cultura en diferentes circunstancias y relaciones en el interior y exterior del grupo; (2) se identifican y se identificaban grupos domésticos y comunidades dispersos; (3) había y hay centros ceremoniales; (4) se generaban y se generan relaciones asimétricas interculturales que han tenido los 
yoremes de manera cotidiana o esporádica con otros grupos étnicos indígenas y no indígenas, y (5) se generaban y se generan dinámicas lingüísticas y se ha mantenido la diversidad de festividades como parte de la manifestación de su cultura (Sandoval, Guerra y Ruiz, 2012).

En relación con un territorio, los pueblos prehispánicos que habitaban lo que es el norte de Sinaloa y sur de Sonora constituyeron importantes núcleos poblacionales. A partir de la Conquista, estos grupos fueron desplazados, desterritorializados y menguados por la política, el poder, la economía y la religión, hasta nuestros días (Sandoval, Guerra y Ruiz, 2012).

Las evidencias arqueológicas apuntan a que había una gran tradición ancestral yoreme. Este grupo precolombino formó parte de la región cultural denominada Aridoamérica y recorría, según su característica seminómada, los actuales estados de Baja California, Sonora, Sinaloa, Chihuahua y Durango (Carpenter, 2009).

Antes de la llegada de los españoles a Sinaloa, existían grupos étnicos bien definidos que constituían importantes núcleos poblacionales, proto yuto aztecas, que pudieron haberse consolidado debido al cultivo del maíz en el inicio del holoceno tardío, alrededor de 2500 años a.C. Este es un dato importante, porque para el despojo de las tierras se alegaba que los indígenas no hacían producir la tierra; por el contrario, había una antigua tradición de cultivos diversos que de manera autosustentable mantenían el consumo interno, sin excedentes, pues no se pensaba desde la perspectiva capitalista. Además, se dispone de evidencia de que mantenían intercambios comerciales muy importantes; los ancestros prehispánicos de esta etnorregión participaban en redes de intercambio regional y rutas de permuta que movían bienes entre las sociedades mesoamericanas y las comunidades de agricultores en el norte de México y sur de Estados Unidos (Carpenter, 2009).

La fuerte avanzada de los españoles en el territorio yoreme se dio con la construcción del fuerte entre 1605 y 1610, para posteriormente fundar las misiones a cargo de los jesuitas, cuyo propósito era transformar a los indígenas en agricultores sedentarios que pagaran un tributo, proveyeran trabajo y fueran cristianos de conformidad con las normas religiosas españolas del catolicismo (Jakson, 2001).

Lo interesante aquí, en relación con los colonos socialistas, es que la política de los jesuitas fue el establecimiento de los yoremes en pueblos de misión en una pequeña comunidad. Es decir, si los diferentes grupos indígenas que habitaban el norte de Sinaloa se conformaban en poblados con cierta organización social, 
los jesuitas indujeron otras formas de comunalidad, lo cual queda pendiente para futuras indagatorias discutir las diferencias entre las comunidades previas y posteriores a las misiones jesuitas.

Estas comunidades misionales resultaron ser muy eficientes, a tal grado de que el gobierno español lo empleó en la mayor parte de las provincias de la frontera norte de la Nueva España, convirtiéndose en una institución de disciplina, reeducación y aculturación de los indios dominados (Almada, Medina, y Valle, 2007). Los misioneros estaban presentes en todos los asuntos de la comunidad, específicamente en la supervisión de la producción agrícola; a ellos les correspondía administrar el temporal (Gaxiola y Velarde, 2009). De aquí también la evidencia de que las tierras no sólo no estaban ociosas antes de la llegada de los españoles, pues el cultivo del maíz ya era parte de la cultura indígena, los jesuitas también modificaron la agricultura, al menos en el estado de Sinaloa.

Por ejemplo, establecieron un sistema bipartita de división de la tierra cultivable: la que se destinaba a la misión, trabajada colectivamente por la población masculina, y las milpas que los nativos trabajaban para su sustento (Almada, 2000). Llama la atención que es un esquema muy parecido a la posterior organización de los colonos americanos.

Cuando los misioneros tuvieron que salir las comunidades indígenas quedaron nuevamente expuestas a la pérdida de sus tierras y a la dispersión debido a la alteración de la organización social que se había construido bajo la dirección de los jesuitas (Gaxiola y Velarde, 2009).

Ante este nuevo contexto, los yoremes optaron por la resistencia activa con base en innumerables levantamientos armados para afrontar de esta manera las injusticias del avance español. Las batallas más relevantes fueron las de 1740 y 1769, todas en el contexto de rebeliones ante el incremento de las presiones de los colonos para despojarlos de sus recursos naturales, su cultura y su territorio.

El 4 de febrero de 1824, siendo ya México independiente, se instaló el Congreso Constituyente del Estado Interno de Occidente, que funcionó brevemente hasta 1831, pero dio cambios significativos en el territorio y la estructura de la sociedad indígena y no indígena. Esto provocó violentas reacciones de los indígenas que los motivaron a proponer la creación de un gobierno indígena independiente de los blancos. Lo que sugiere que para ese entonces seguía existiendo un gobierno indígena con capacidad de acción política y que poco a poco fue diluyéndose. A partir de aquí, las luchas de los yoremes contra los yoris (los no indios, los que no respetan la ley tradicional) continuaron de manera intermitente. Juan Banderas, líder yaqui, planteó incluir 
mayos, ópatas, pimas, eudeves, pápagos, piatos, seris y apaches, para enfrentar a los ladrones de tierras, pero, como siempre sucedió, fueron controlados en 1832 (Almada, 2000).

El problema era que los indios que no cumplían con los estándares de comportamiento en México producían mucha ansiedad para los funcionarios. En particular las tribus yaqui y apache en el norte de México eran consideradas sospechosas en tiempos de paz. Su sola presencia era percibida como un impedimento para el progreso ya que no se quería dar la impresión internacional de ser una nación incivilizada. De esta forma, estas tribus tendrían que ser exterminadas. La guerra con los yaquis se justificó bajo la idea de que México tenía el derecho legítimo de asimilar a este pueblo a la economía y al todo nacional (Kinney, 2016). Los Yaquis han subsistido con muchas dificultades hasta nuestros días, asumiendo la protección y defensa de su territorio y de su agua, su defensa entre otras es "nosotros llegamos a esta tierras antes de que México fuera una nación" por la tanto "la tierra nos pertenece por derecho", por ser los originarios en el territorio.

Actualmente, la mayor densidad de población yoreme mayo se ubica en el norte de Sinaloa y sur de Sonora en una región cuya topografía varía del nivel del mar en su embocadura en el Golfo de California (Mar de Cortés) a las cumbres de las montañas más altas de la Sierra Madre Occidental a unos 2290 msnm, y está conformada por tres zonas fisiográficas: la serrana, los valles y la costa (Carpenter, 2009); en esta misma distribución la encontraron los colonos. Las comunidades yoreme mayo se distribuyen de acuerdo con la referencia geoestadística del Instituto Nacional de Lenguas Indígenas (INALI) (2009) en Sinaloa en los municipios de El Fuerte, Choix, Guasave, Sinaloa, Angostura y Ahome (donde se encuentra Topolobampo), y en el estado de Sonora en Álamos, Quiriego, Benito Juárez, Cajeme, San Ignacio, Río Muerto, Navojoa,

Etchojoa y Huatabampo. Este espacio, al ser compartido por un grupo indígena que tiene una dinámica sociocultural propia, se contextualiza como territorio y adquiere de manera específica el significante de etnorregión yoreme.

Si bien entre los mayos de Sinaloa y los de Sonora hay una hermandad de origen y de tradición, la diferencia esencial se da en términos de variantes lingüísticas. Su lengua pertenece a la familia tara-cahita, del tronco yuto-nahua, emparentada directamente con la yolem'me jia 'ki y guarijio (Moctezuma, 2001).

Se autodenominan yorem 'mem (los que respetan); su lengua, yoremnokki, pertenece a la familia tara-cahita, como se había mencionado, del tronco yuto-nahua (INALI, 2009); según la tradición oral del grupo, la palabra mayo significa «la gente de la ribera» (Moctezuma y López, 2007). 


\section{Las relaciones interculturales}

El caso del surgimiento de Topolobampo es complejo, la interpretación de cada aspecto no es directa ni sencilla, implica análisis más profundos de cada uno de ellos. En su época había una gran expectativa a nivel nacional, los periódicos de la ciudad de México dejaban ver claramente que era necesario que los colonos influyeran para que todo el país llegara a una economía moderna; lo que justificaba plenamente el sacrificio de las tierras indígenas (Kinney, 2016).

En este cambio de dueño, de manos indígenas a no indígenas, es como comenzó a desarrollarse, décadas después, el monocultivo que daría grandes beneficios a los terratenientes, pero la ausencia de la agricultura diversa para el autoconsumo intensificó los cuadros de pobreza en la población desterrada.

En aquel entonces, no se entendía que la economía indígena, adelantándose a Marx y a Lenin, se separaba del capitalismo, pues se acoplaba mejor con la naturaleza minimizando los impactos ecológicos, su vida armonizaba con la sustentabilidad y muchos aspectos bioéticos, como los que hoy enfrentamos, ya estaban resueltos.

Es de interés hacer notar que los yoremes de aquella época mantenían organizaciones comunales sin propiedad privada desde tiempos precolombinos y que las amplias zonas de tierra sin habitar se debían también a su carácter seminómada, pues emigraban según las estaciones del año.

Anteriormente, los pueblos indígenas de México mantenían un sistema de tenencia de tierra y de propiedades que se basaba en una estructura comunal de la economía. Este sistema comunalista e idílico se remontaba a tiempos anteriores a la Conquista española.

Es sarcástico que el gobierno mexicano diera el apoyo para la empresa socialista de propiedad comunal entre americanos a la vez que trabajaba en desmantelar un sistema de comuna similar que ya tenía la población indígena (Kinney, 2016).

Si los socialistas que proponían la comuna no hubieran sido racistas, se habrían ido a vivir con algún grupo étnico originario, de México al menos. Esto les hubiera costado menos esfuerzo. Pero veían a los indígenas, a su organización y su economía, como atrasadas, pues no participaban en los nuevos esquemas económicos que en nuestros días ponen en peligro la sustentabilidad mundial. 
Muchos colonos expresaban que la población india era incapaz de planificar con anticipación, la evidencia más común de esto era que no estaban dispuestos o nunca habían considerado ahorrar dinero para comprar mantas para las noches frías. Ante el frío, ellos prendían una gran fogata, danzaban y luego se tendían a dormir en la orilla alrededor del fuego; se despertaban casi congelados cuando el fuego se apagaba y volvían a encender otra fogata (Kinney, 2016).

La propuesta socialista, al igual que todas las comunistas, no consideró a los indígenas desde una perspectiva de reivindicación. Es cierto que hubo colonos que se dignaron a intercambiar cultura y educación con algunos pocos yoremes, pero no fue el caso de la mayoría, cuyo sueño más bien se trataba de un socialismo con los de la propia cultura o en todo caso de un interculturalismo limitado.

Lo que menos le interesaba era la vida de los yoremes y jamás manifestaron que deseaban interesarse en ellos; su comuna no les dio importancia, estaban o venían, como se decía en la época, junto con las tierras, así como las plantas y animales. De hecho, para Owen era preferible asociarse con magnates capitalistas, terratenientes y hombres poderosos, que, con las comunas indígenas, que dicho sea de paso tenían ideas semejantes a los de sus supuestos ideales socialistas.

Todos los hechos históricos mencionados sucedieron en una misma etnorregión yoreme en la que había y sigue habiendo una fuerte presencia de este grupo étnico. La relación etnia y región está vinculada con la identidad india en tres espacios, que fueron agredidos en los procesos colonizadores: (a) los territorios sagrados, que desde la cosmovisión no indígena pudieron haber sido catalogados de 'baldíos'; (b) los de la vida social, correspondientes sus rutas comerciales y de intercambio, de cacería y de pesca, etc., y (c) los de la dinámica doméstica, sus lugares habitacionales y propios de su organización como etnia.

En todo el proceso histórico descrito, los yoremes continuaron sufriendo los procesos de colonización y fueron perdiendo la esperanza de su autonomía como pueblo; su antiguo territorio fue rebasado poco a poco por el asentamiento de no indígenas, primero españoles, luego por criollos y mestizos y en el caso que nos ocupa de colonos extranjeros, que en todo este proceso de alteración se fue rompiendo el equilibrio natural y social, generando una serie de desajustes que incidieron en su etnicidad. Lo que hoy se observa son los fragmentos dispersos y pulverizados de lo que alguna vez, en épocas precolombinas, fue una gran nación.

Claro está que hubo intercambios positivos en las interrelaciones entre los colonos y los yoremes. Hay muchas evidencias de que hubo apoyos importantes entre algunos nativos y miembros de la colonia, como el caso de Fernando Palomarez, quien convivió con miembros de la colonia y pudo adquirir una educación sobresaliente, 
pues se le reconocía como políglota; la historia muestra cómo posteriormente se distinguió como uno de los más destacados militares magonistas de la Revolución Mexicana (Torúa, 2017).

Como parte de un proyecto de modernización liberal y la intensificación del capitalismo, la Ley Lerdo exigió la individualización y el desconocimiento del carácter comunitario de los territorios indígenas. Esta legislación formó parte de las políticas del interculturalismo liberal y buscó, mucho antes de la Revolución Mexicana, borrar a los indios del mapa, invisibilizándolos, excepto a aquellos que se sublevaban y que los catalogaban como bandidos; a estos últimos tenían que exhibirlos públicamente y aprovecharlos para denigrar la cultura a la que pertenecían.

En esta postura racista se consideraba que los indígenas eran flojos e ignorantes y no sabían cómo explotar adecuadamente la tierra. Con un pensamiento tramposo y perverso, en esa época les quitaron territorios de caza, lugares sagrados, lugares de recolección de frutas y de etnocultivo, que formaba parte de sus tradiciones ancestrales y que aseguraban su sustento.

Desde el punto de vista indígena, era una época en la que, a pesar de las relativamente recientes independencias de México y Estados Unidos, la persecución, el hostigamiento, las vejaciones y en general toda la violencia racista, persistía hacia los pueblos indígenas que prácticamente habían perdido su propio gobierno y todo poder de defensa. Pero aún había importantes levantamientos armados.

Aquí es importante resaltar que muchas veces el racismo y la discriminación no se presentan en el trato directo entre las personas; este es un fenómeno más estructural. Por ejemplo dos hechos resaltan a) uno es que mientras los colonos pudieron hacerse de algunas tierras, a los indígenas se les despojaba de ellas, pero el trato entre ellos fue generalmente amable y cordial y b) otro es que a pesar de que los colonos valoraban las ideas indígenas de propiedad comunal, nunca hubo el intento de incluir a los indios como parte de la colonia, esto significó definitivamente una fisura en su discurso de igualitarismo racial, que era poco común en su época que revelaba contradicciones entre su discurso de bienvenida universal y admiración por los valores indígenas y el rechazo a que éstos fueran miembros de la comunidad (Kinney, 2016).

Chrisian B. Hoffman una vez escribió: 'Permítanme expresar aquí, en nombre de nuestra gente, la buena opinión que tenemos de nuestros vecinos nativos, amables, gentiles, de maneras simples, los indios son vecinos agradables y sencillos; no son un obstáculo ni una amenaza para nuestro progreso, por el contrario, estos niños de la naturaleza tienen muchas ideas en común con nosotros. Su tenencia de la tierra es similar a la de nosotros. 
Un indio me dijo el otro día, cuando le preguntaba cuánto me cobraría por el uso del poso de su propiedad: "Dios hizo el agua y mientras haya, puedes compartirla”. Hablando de la tierra que cultiva, dijo:" No la venderé, es mi hogar, Dios hizo toda la tierra y cualquiera tiene derecho a usarla, tengo un mejor derecho sobre ella que alguien más, sólo porque la he cercado y cultivado". A pesar de pensar esto, Hoffman sugería no pagar a los indios más de 50 centabos al día por su trabajo. Este lenguaje condescendiante frecuentemente fue y ha sido usado para esconder y justificar la negación de los derechos de los pueblos indígenas en América (Kinney, 2016:152).

La forma en como algunos colonos como Owen, Hoffman y Jhonston fueron beneficiados formó parte de la estructura racista hacia los indígenas y la discriminación que ya tenían. Los inmigrantes norteamericanos eran blancos y, aun con el espíritu socialista, el racismo soterrado persistía.

Los apaches fueron el mejor ejemplo de racismo violento; eran una etnia que puso en evidencia las políticas interculturales con los indígenas en ambos países; lo único que deseaban los gobiernos mexicano y estadounidense era exterminarlos, y en su intento lograron mancillar poblados enteros de este y de paso de otros grupos indígenas, principalmente yaquis; en el caso mexicano se logró su exterminio, pues este grupo apache ya no forma parte oficial de la diversidad étnica nacional, pero logró subsistir con muchas penurias en Estados Unidos.

La hostilidad de los indígenas no fue gratuita. No se debía a su salvajismo, sino a su desesperación y a su impotencia debido a la violencia recibida y al despojo del que históricamente fueron víctimas. En esa época se libraron las últimas batallas de los yoremes; después de eso, continuó el sometimiento que ha sido absoluto. Sin embargo, hay que aclarar que no era la intención de los colonos norteamericanos lesionar a ninguna persona, si bien había una especie de clima de época en relación con el trato de los indígenas, su interés no se centraba en las relaciones con otros, sino en el desarrollo de su proceso de unión en el desarrollo de su sueño socialista. En general, no venían con algún plan de relación intercultural, aun cuando sí lo pensaron varias veces. Respecto de la idea de que la colonia fuera sólo para los americanos, algunos de ellos como Marie Howland argumentaba que sería deseable un porcentaje de mexicanos (no indígenas) y alertaba que aquellos que sintieran temor o estuviera afligido por prejuicios de raza se alejaba de los principios por los que se encontraban allí (Kinney, 2016).

El feminismo propuesto por algunas idealistas de la colonia luchaba contra la imposición de roles éticos y estéticos y ligado a nuevas propuestas en el orden sexual y por ende familiar y laboral. 


\section{La intención política}

La dinámica sociointercultural presenta dos formas de interculturalismo, el estadounidense, cuyas acciones se basaban en la política del "destino manifiesto" y la mexicana que luchaba al exterior por que se respetara su autonomía y su independencia mientras que al interior ejercía una política de exterminio económico y cultural para con los pueblos indígenas. En la intensión política de la instalación de la colonia hay muchas cosas contradictorias en la historia del surgimiento de Topolobampo:

1) Condiciones propicias para la invasión. Pareciera que ingenuamente el gobierno mexicano siguió poniendo las condiciones propicias para la invasión y el posterior reclamo de independencia de las regiones del país, al permitir que extranjeros no sólo ocuparan los territorios, sino que tuvieran gobernabilidad sobre los mismos. No estamos diciendo con esto que los colonos fueran en general malintencionados, pues la historia muestra la nobleza de su causa, sobre todo los verdaderos socialistas utópicos. Pero sí es importante recalcar que las condiciones estaban dadas para un nuevo enfrentamiento entre las dos naciones. Habiendo tantos problemas en Sinaloa, las posibilidades de que el asunto de la colonia se saliera del control eran excesivas; con los continuos conflictos, alguno de los bandos podía violentar a los colonos y esto ser motivo para un conflicto internacional. Es evidente de que había un fuerte interés nacional e internacional en los proyectos de Owen, pero desde una perspectiva actual la intromisión de empresas estadounidenses se observa muy riesgosa. Esto indica que las políticas gubernamentales mexicanas tenían tremendas contradicciones, y sobre todo que atentaba directamente contra la soberanía nacional mexicana.

2) Altas esferas. Como se ha mencionado, es tremendamente intrigante que la incursión de Owen en México haya sido a través de personajes de altas esferas gubernamentales, norteamericanas y mexicanas, y algunos de ellos militares de alto rango. Esto, de alguna manera, no casa con los ideales socialistas y con lo que fue la realidad de una inocente comuna con personas de un país que vivirán en otro. Queda claro que Owen no era un simple ingeniero, pero de acuerdo con los niveles que se manejó se demuestra que tenía cierto poder político y económico. Los que sí pasaron muchas penurias fueron los colonos, tanto que no lograron consolidar el proyecto de vida que tenían.

3) Lo escrito vs los hechos. Genera controversia que los ideales escritos de Owen contrastaran con su relación con la comuna, pues prácticamente se desligó de muchos asuntos cotidianos; es decir, en la colonia vivieron los interesados en el socialismo, mientras él tomaba la postura del gran empresario ferrocarrilero, de bienes y raíces y quizá de operador político norteamericano. 
4) Adquisición desmedida de territorio. Otro aspecto que no concuerda con el socialismo utópico de Owen es el continuo interés de adquirir más y más tierras, quizá debido a las circunstancias que se generaban en el marco de las negociaciones con empresarios y funcionarios gubernamentales a los que les debía el favor, o tal vez como estrategia de protección para la misma colonia, de acuerdo con su plan de crecimiento.

5) Ubicación de la colonia. Genera suspicacia que habiendo tantos lugares en Estados Unidos, con la reciente gran cantidad de tierras adquiridas por Estados Unidos, ¿por qué tendría que ubicarse la colonia en Sinaloa? Además, es controvertido que en determinado momento ya no se trataba de una colonia, sino de algo de mayor envergadura; aun hoy, se trata del territorio de varios municipios involucrados. No exclusivamente de Topolobamo, sino de una gran cantidad de territorio del norte del estado de Sinaloa, donde, dicho sea de paso, hay cientos de pequeños fraccionamientos. La población excesiva de la colonia, las dificultades de escasez de recursos, la organización y los problemas al interior resultaron difíciles de sobrellevar.

6) El falso oasis. Es de hacer notar que Owen llega en un periodo de mucha hambruna en Sinaloa, lo que también vuelve evidente que el edén que promovía, independiente de la belleza natural, se trataba solo de publicidad.

Desde el punto de vista de negocios, se trató del desarrollo de una empresa en la que Owen consiguió el lugar, las tierras, los inversionistas, la publicidad y en vez de hacer divisiones en lo que hoy conocemos como fraccionamientos, lo manejó como una comuna socialista. Con esto no estamos afirmando que los comuneros hayan tenido esa intención, pero algún estratega en otro nivel pudo haber observado la oportunidad.

Owen supo conjugar en su utopía varias ideas que causaron gran interés: (1) la construcción de un puerto, (2) el inicio del ferrocarril que convendría tanto a México como a Estados Unidos, (3) un lugar idílico para los socialistas, y (4) la posibilidad de grandes negocios en bienes y raíces, entre otros.

En los últimos años, estaba cansado y simplemente dejó de luchar; abandonó el proyecto al que había dedicado prácticamente toda su vida. Después de Owen, otro norteamericano continuó con actividades de relevancia en la región; Johnston desarrolló el interés de la industria azucarera. 
Ambos, Owen y Johnston, no eran personas humildes, sino influyentes que tenían poder nacional e internacional. Independientemente de sus reales intenciones, lo que sí es cierto es que formaron parte importante del tejido social para el surgimiento de Topolobampo y lo que hoy es la ciudad de Los Mochis, en el Estado de Sinaloa.

\section{Conclusiones}

La dinámica sociointercultural de la colonia de Topolobampo se describió desde dos diferentes aristas: a) desde las relaciones interculturales donde se incluyen los aspectos del feminismo, del racismo y la discriminación y de las ideas del socialismo limitado y utópico y b) Desde el plano de la intensión política, donde se incluyen aspectos de la economía para el desarrollo urbano y agrícola de la región.

\section{Relaciones interculturales.}

El proceso descrito presenta dos formas de interculturalismo, la estadounidense y la mexicana. En la estadounidense, a través de la política del "destino manifiesto” los demás países tenían que subordinarse a su cultura e internamente las etnias autóctonas debieron ser sometidas violentamente y recluidas en reservas, para dar paso a la conformación de una nación intercultural de dominio de inmigrantes europeos. En la mexicana no se pretendía ninguna injerencia con ningún país, al contrario, se luchaba por que se respetara su autonomía y su independencia e internamente había una política de exterminio económico y cultural para con los pueblos indígenas.

Independientemente de las ideas que se escribieron alrededor de la colonia, habría que cuestionarse si realmente lo que se propuso en la práctica de la colonia fue un socialismo o se trataba del mismo pensamiento capitalista con algunas restricciones, por ejemplo, en la compensación por el trabajo, las economías de escala de los recursos públicos, la organización de las familias, entre otros aspectos.

El experimento socialista se encontró siempre matizado por los grandes negocios y por las luchas ideológicas internas que motivaron su ruptura.

Por cuestiones racistas las propuestas de organización comunal y socialista indígena no fueron consideradas, pues se encontraban fuera de las propuestas del socialismo utópico, en donde los indígenas no formaban parte de los elementos de los modelos propuestos desde occidente. Es decir, la propuesta socialista no se encontraba fuera de preceptos racistas y discriminadores. 
Se cuestionaba a los indios por su falta de planeación, son embargo ahora se hace evidente la imposibilidad de una verdadera planificación y los gobiernos planificadores (socialistas o capitalistas) se ponen en tela de juicio.

El racismo ejecutado en perjuicio de los yoremes se presentaba ante jerarquías de color, de estatus económico y de conocimientos tecnológicos.

\section{A. La intención política}

El caso del surgimiento de Topolobampo es complejo, la interpretación de cada aspecto no es directa ni sencilla, implica análisis más profundos de cada uno de ellos. ¿Cómo es que el gobierno mexicano permitió la instalación de una colonia de norteamericanos a menos de 50 años de haber perdido más de la mitad de su territorio? La respuesta no es simple y se pueden enumerar diferentes aspectos: 1) a pesar de los posibles resentimientos posteriores a la pérdida, existen también sentimientos de agradecimiento por el apoyo recibido ante la posterior intervención francesa, 2) la necesidad de adquirir tecnología y particularmente el desarrollo de vías férreas podía justificar algunos riesgos en cuestión de soberanía, 3) la estrategia económica de hacer producir las tierras que bajo aquellas circunstancias se encontraban, desde la perspectiva no indígena, abandonadas, 4) el malinchismo y autoracismo mexicano que busca que algún extranjero venga a mejorar la raza y a solucionar los problemas económicos y de organización del país y 5) otras agendas que no han sido esclarecidas del todo, como la de las poderosas organizaciones masónicas de aquella época que eventualmente presentan cierto asomo en los hechos.

Los resultados posteriores a los hechos tienen un carácter dialéctico, pues por un lado se encuentra el despojo de las tierras indígenas y la afectación de su cultura y del patrimonio que ahora es de gran valor nacional, por otro está la gran producción agrícola que ahora representa esta zona a nivel nacional, aunado al incuestionable desarrollo de las ciudades mencionadas tales como Los Mochis y Topolobampo.

Pero al seguir con la dialéctica el actual aprecio por los recursos naturales apuntan a que la economía indígena presentaba esquemas más sustentables que los que posteriormente se vivieron con los esquemas de producción monocultivo que quedó como herencia de la estancia de los colonos en la región.

Los negocios de Owen y su adquisición desmedida de territorio, contradecía la práctica socialista de la colonia.

El hecho es que las condiciones estuvieron propicias para una invasión, en todo el proceso estuvieron involucrados personajes de altas esferas políticas de México y de Estados Unidos, pero el desenlace fue quizás inesperado para los que estuvieron involucrados. Aún se encuentran voces románticas sobre lo que fue Topolobampo, la ciudad socialista de occidente. 


\section{Referencias bibliográficas}

Almada, I. (2000). Breve historia de Sonora. México, Fondo de Cultura Económica.

Almada, I. Medina, J. y Valle, M. (2007). Hacia una nueva interpretación del régimen colonial en Sonora, descubriendo a los indios y redimensionando a los misioneros, 1681-1821. Región y Sociedad, Hermosillo, vol.19 sep-ene., 237-66.

Carpenter, J. P. (2009). Historia cultural de la ocupación prehispánica del valle del río Fuerte.

García, N. (2004). Diferentes, desiguales y desconectados: mapas de la interculturalidad. Barcelona, Gedisa.

García, A. (2020). Owen en Topolobampo, Sinaloa. Aventuras y desventuras, cooperación y competencia, una actualización de la discusión. En García, Alejandro y Guerra, Ernesto. (Eds.). Owen en Topolobampo, México: interculturalismo, contexto y experiencia, México: Del Lirio, UANL y UAIM, 13-130.

García, J.M., López, J., y Ruiz, D. (2000). Introducción histórica a la filosofía del Estado (III). Los precursores del socialismo moderno. Filosofía, política y economía en el Laberinto, España, Universidad de Málaga, No. 3. Recuperado de https://dialnet.unirioja.es/servlet/articulo?codigo=2020498.

Gaxiola, S. L., y Velarde, S. (2009). La población indígena en la jurisdicción de El Fuerte en el siglo XVIII. López, Gilberto, Mercado Alfonso, y Heredia María (coord.), El patrimonio histórico y arqueológico del antiguo Fuerte de Montesclaros. México, Instituto Nacional de Antropología e Historia, Universidad Autónoma de Sinaloa, H. Ayuntamiento de El Fuerte, 145-155.

Gouy-Gilbert, C. (1985). Una resistencia India: Los yaquis. México, Centro de Estudios Mexicanos y Centroamericanos.

INALI. (2009). Catálogo de las lenguas indígenas nacionales: variantes lingüísticas de México con sus autodenominaciones y referencias geoestadísticas. Instituto Nacional de Lenguas Indígenas.

Iribarne, M. (2020). Utopian dreams in the new world and for the new woman: the influence of utopian socialism in firts wave feminism. The case of Mary Howland and Topolobampo's community. Hispania Nova, Revista de Historia Contemporánea. (18) 381-418.

Jakson, R. H. (2001). Una frustrada evangelización: las limitaciones del cambio social, cultural y religioso en los 'pueblos errantes' de las misiones del desierto central de Fronteras de la Historia (6), 7-40.

Katscher, L. (1906). Owen’s Topolobampo Colony, México. The American Journal of Sociology. 12(2), $145-175$.

Kinney, E.R. (2016). American Emigrants: Confederate, Socialist and Mormon Colonies in Mexico. Tesis para obtener el grado de Doctor of Philosophy. Universidad de Texas en Austin.

López, H. E. (2007). Los mayos de Sinaloa: esbozo etnográfico y regional. Cuicuilco, 14(39), 11-33.

Martínez (2000). Los Mochis, orígenes y fundación. Universidad de Occidente. 
Mejía, F. (2011). Tres miradas estadunidenses a México. Recuperado de https://www.proceso.com.mx / 28 6680/tres-miradas-estadunidenses-a-mexico.

Moctezuma, J. L. (2001). De pascolas y venados. Adaptación, cambio y persistencia de las lenguas yaqui y mayo frente al español. Siglo XXI, El Colegio de Sinaloa.

Moctezuma, J., y López, H. (2007). Mayos. México, Comisión Nacional para el Desarrollo de los Pueblos Indígenas.

Moore, Ch. (1975). Paradise at Topolobampo. The Journal of Arizona History, 16(1), 1-28.

Nakayama, A. (1996). Sinaloa, un bosquejo de su historia. Universidad Autónoma de Sinaloa.

Ochoa, J. A. (2000). Bachomo, los días del gato. Crónica indígena de la Revolución. México: Creativos7.

Ochoa, J. A. (2018). Bäkampo. Reseña histórica del ejido Las Vacas. Del Lirio, UAIS.

Ortega, S. (1999). Breve historia de Sinaloa. El Colegio de México. Recuperado de http://bibliotecadigital. ilce.edu.mx/sites/estados/libros/sinaloa/html/sinalo.html.

Owen, A. K. (1890). Integral Co-opration. John W. Lovell Company. Universidad de Harvard

Pérez, T. (2000). La guerra hispano-estadounidense del 98 en la prensa mexicana. Historia Mexicana, 50, (2), 271-308.

Sandoval, E. A. Guerra, E. Ruiz, F. (2012). Etnorregión yoreme en el norte de Sinaloa. En Guerra, E. A. Sandoval y F. Ruiz (coords), Etnoregión yoreme en Sinaloa. Del Lirio, UPN, UAIM.

Santana, A. (2007). La revolución mexicana y su repercusión en América Latina. Latinoamérica, Revista de Estudios Latinoamericanos (44), 103-27.

Torúa, A. (2017). Fernando Palomarez, el indio mayo y militante clave en el movimiento magonista. Praxislibertaria, $\quad$ Represión, $30 \quad$ junio, Recuperado de: https://praxislibertaria.wordpress.com/2017/06/30/mexico-articulo-fernando-palomarez-el-indio-mayo-ymilitante-clave-en-el-movimiento-magonista/.

Valadés, J. (1939). Topolobampo, la metropoli socialista de occidente. El Trimestre Económico, 6(23), $349-98$. 